\title{
Survey Protocol for the Northern Leopard Frog
}

\section{Fish \& Widilife Division}

RESOURCE STATUS AND ASSESSMENT BRANCH

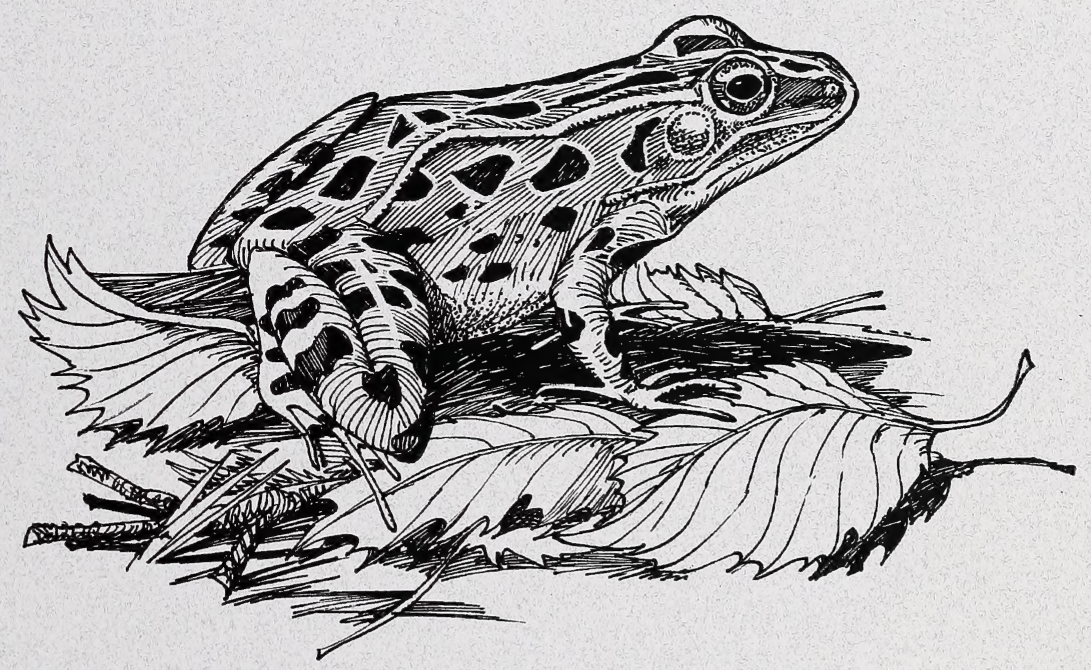

Alberta Species at Risk Report No. 43 
Digitized by the Internet Archive in 2016

https://archive.org/details/surveyprotocolfo00kend_0 


\title{
Survey Protocol for the Northern Leopard Frog
}

\author{
Kris Kendell
}

Alberta Species at Risk Report No. 43

February 2002

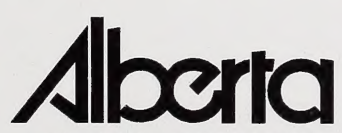

SUSTAINABLE RESOURCE DEVELOPMENT

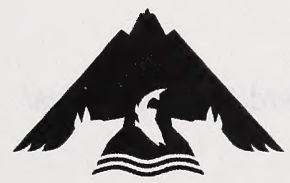

Alberta Conservation Association 
Publication No.: I/060 (Printed, On-line Edition)

ISBN: 0-7785-2016-1 (Printed Edition)

ISBN: 0-7785-2162-1 (On-line Edition)

ISSN: 1496-7219 (Printed Edition)

ISSN: 1496-7146 (On-line Edition)

Illustration: Brian Huffman

For copies of this report, contact:

Information Centre - Publications

Alberta Environment

Main Floor, Great West Life Building

9920108 Street

Edmonton, Alberta

Canada

T5K 2M4

Telephone: (780) 422-2079

\section{OR}

Information Service

Alberta Environment

\#100, 311512 Street NE

Calgary, Alberta, Canada T2E 7J2

Telephone: (403) 297-3362

OR

Visit our web site at:

http://www3.gov.ab.ca/srd/fw/riskspecies/

This publication may be cited as:

Kendell, K. 2002. Survey protocol for the northern leopard frog. Alberta Sustainable Resource Development, Fish and Wildlife Division, Alberta Species at Risk Report No. 43, Edmonton, AB. $30 \mathrm{pp}$. 


\section{DISCLAIMER}

The views and opinions expressed are those of the author and do not necessarily represent the policies or positions of the Department or the Alberta Government. 


\section{TABLE OF CONTENTS}

Acknowlegements vii

Executive Summary viii

1.0 INTRODUCTION

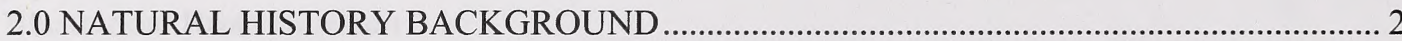

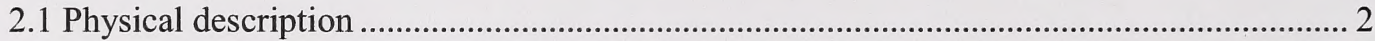

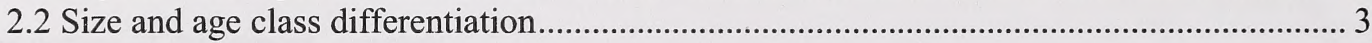

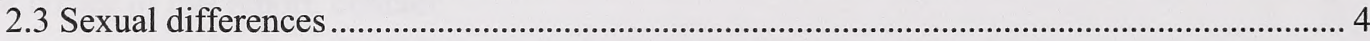

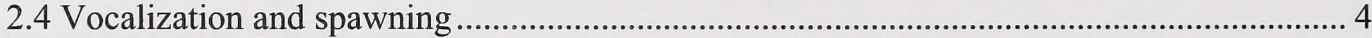

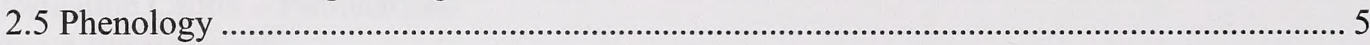

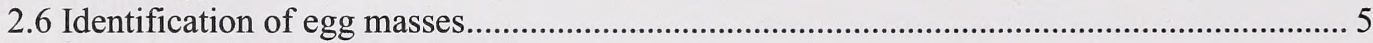

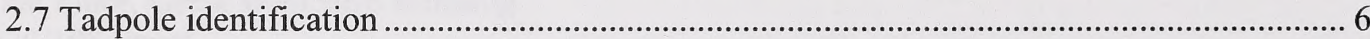

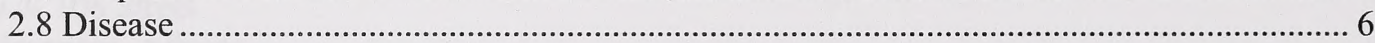

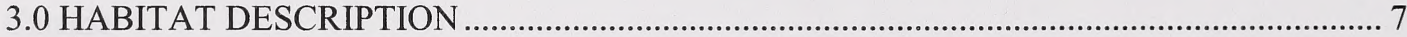

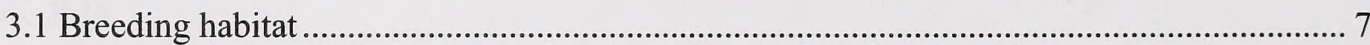

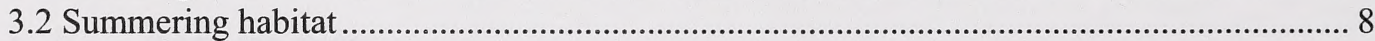

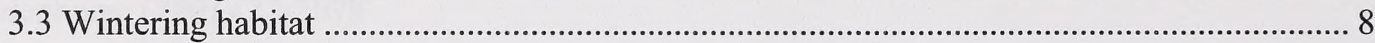

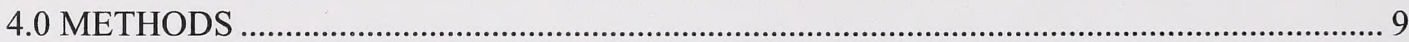

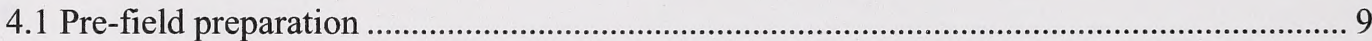

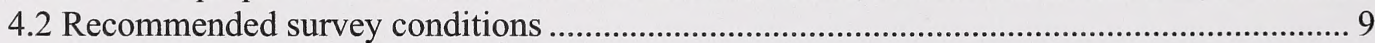

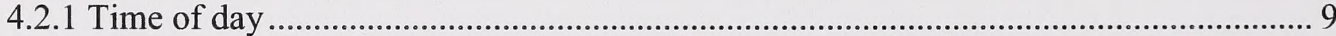

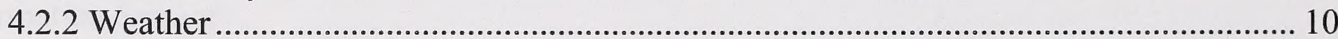

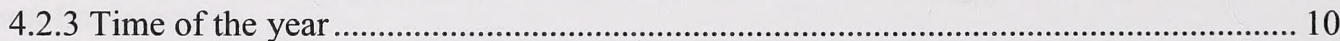

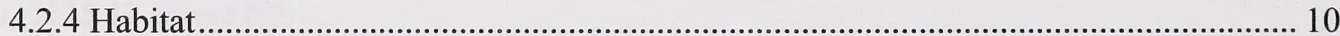

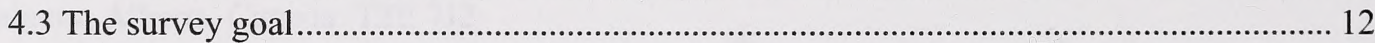

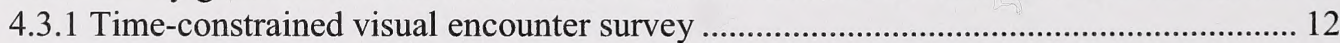

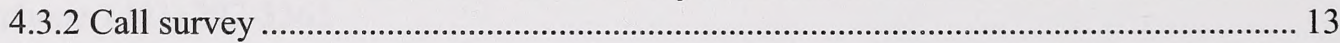

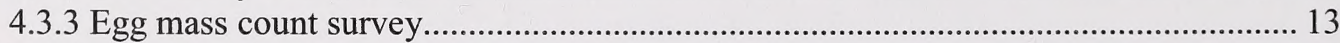

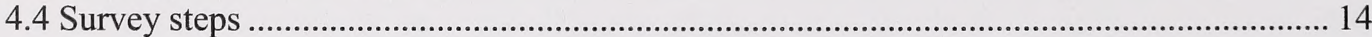

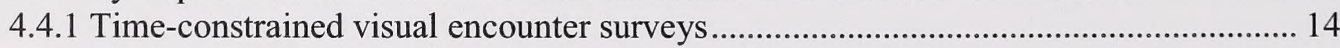

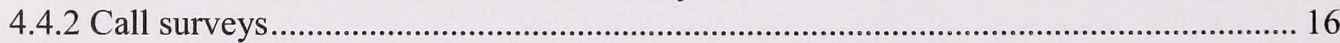

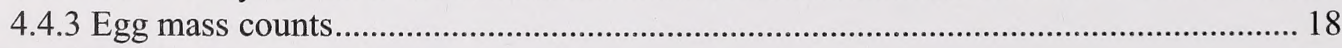

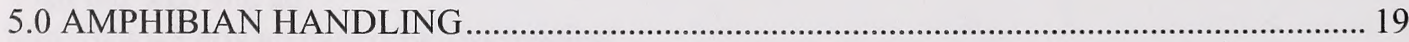

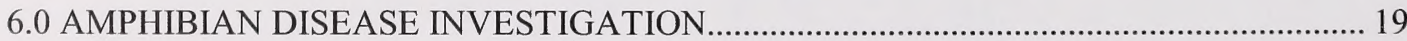

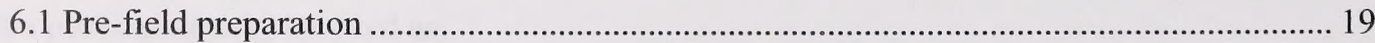

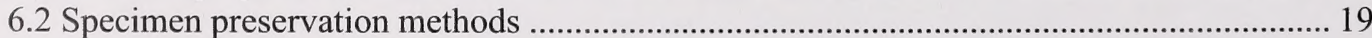

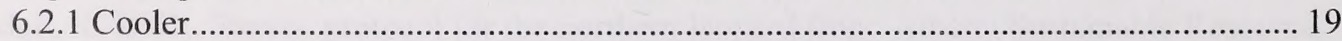

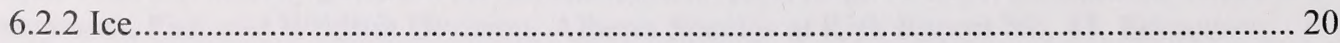

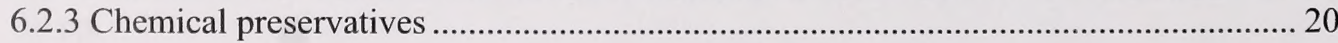

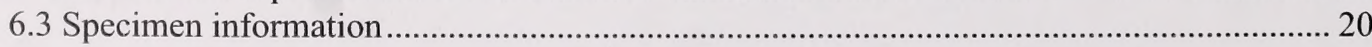




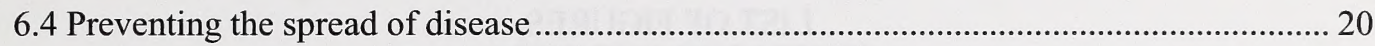

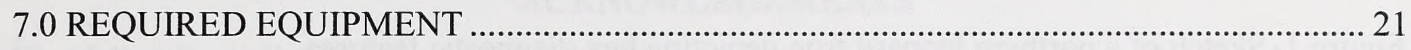

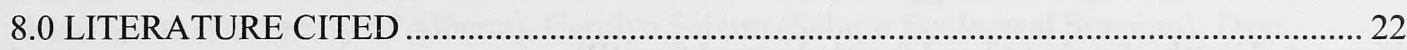

Appendix 1. Photographs of the northern leopard frog. .............................................................. 25

Appendix 2. Northern leopard frog survey data sheet. ................................................................ 26

Appendix 3. Interpretation of northern leopard frog survey data sheet.................................... 28

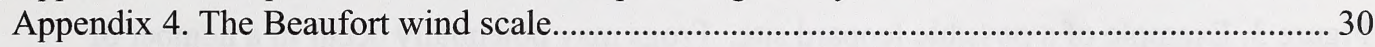




\section{LIST OF FIGURES}

Figure 1. Sketch of a northern leopard frog depicting key diagnostic features.............................. 3

Figure 1. Thumb of male (A) and female leopard frog (B). ................................................ 4

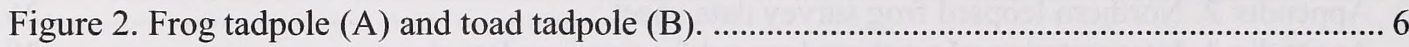

Figure 3. Example of a possible leopard site. Frogs may potentially occur in a number of habitats at the site, depending on the time of the year. $\mathrm{B}=$ breeding habitat, $\mathrm{S}=$ summering habitat, and $\mathrm{O}=$ over-wintering habitat.

\section{LIST OF TABLES}

Table 1. Summary of age class and SVL of leopard frogs suggested by a number of authors. ..... 3

Table 2. Summary of egg mass size and descriptions of the leopard frog, wood frog and chorus frog as suggested by a number of authors

Table 3. Summary of environmental and weather conditions that affects the activity level of leopard frogs.

Table 4. Survey schedule based on habitat type and time of the year.

\section{LIST OF PHOTOS}

Photo 1. Brown phase of the northern leopard frog. Key diagnostic field marks are clearly shown in the photo, including the lightly colored dorsolateral ridges (on either side of the spine), dark spots with light borders and light line on the upper jaw.

Photo 2. Green phase of the northern leopard frog 25 


\section{ACKNOWLEGEMENTS}

The following individuals provided editorial comments and suggestions regarding this document: Brian Eaton (University of Alberta), Carolyn Seburn (Seburn Ecological Services), Dave Prescott (Sustainable Resource Development - SRD), Dawn Birn (Alberta Conservation Association - ACA), Doug Adama (Columbia Fish and Wildlife Compensation Program), Edward Hofman (SRD), Lisa Takats (ACA), Steve Brechtel (SRD) and Sue Cotterill (SRD). 


\section{EXECUTIVE SUMMARY}

This document describes a species-based survey protocol for the sampling of the northern leopard frog (Rana pipiens) in Alberta. The protocol may be adapted for inventories of other amphibian species. Three sampling techniques for the leopard frog are described in the protocol and include a time-constrained visual encounter survey, a call (vocalization) survey and an egg mass count survey.

A natural history background for the northern leopard frog is provided in order to increase the efficiency and productivity of surveys for the species. Under this section, the life history, behavioural strategies and habitat uses of the leopard frog are described. In addition, detailed information on the physical description, size, sexual differences, vocalization, breeding and phenology is discussed. Finally, information on the prevention of disease transfer between survey sites, amphibian-handling procedures and disease investigation procedures are included.

A data sheet specifically designed to record habitat characteristics and other ecological information important for the evaluation and management of the northern leopard frog is included. 


\subsection{INTRODUCTION}

A multitude of survey protocols and techniques regarding the capture and sampling of amphibians have been published (see Heyer et al. 1994). The range of protocols and survey techniques is a reflection of the unique and complex life histories, habitat uses and behavioural strategies of the estimated 4300 to 4500 amphibian species that occur world wide (Vial and Saylor 1993, Zug 1993, McDiarmid 1994). Several examples of specialized inventory techniques involve traps (i.e. minnow trap), PVC pipe, coverboards, debris bags (Pauley and Little 1998), or drift fences with pitfall traps. The most basic of all sampling techniques are variations of "visual encounter" surveys and "calling" surveys.

The purpose of this document is to provide a tailored inventory protocol adapted for a single species, the northern leopard frog (Rana pipiens). If required, the following protocol could be adapted and used for sampling other amphibian species found in Alberta. To increase the efficiency and productivity of leopard frog surveys an accurate and precise inventory protocol and sampling technique is required. Such a protocol must incorporate a variety of considerations with respect to habitat use, phenology and behaviour of the target species.

The following protocol describes a preferred method for sampling the northern leopard frog in Alberta that involves a time-constrained visual encounter survey. Two additional methods are outlined in the protocol for consideration, and involve audio detection for vocalizing male frogs during the breeding season and an egg mass count survey. In all methods habitat characteristics are recorded, as are the environmental conditions during the survey and the actual or estimated number of leopard frogs observed. In the case of call surveys, the number of frogs heard is grouped into categories using a call index. To simplify data collection, a specifically designed data sheet for sampling leopard frogs is included. 


\subsection{NATURAL HISTORY BACKGROUND}

Amphibians possess certain natural history characteristics (phenology, biology and behaviour) that may inhibit some sampling strategies and lead to challenges in conducting inventories. The following factors should be considered before conducting surveys for the northern leopard frog:

- They spend much of the year submerged underwater during hibernation.

- They exhibit crepuscular or nocturnally breeding behaviour.

- They usually breed for only a short period of time during the spring.

- Its' breeding call is rather weak with a limited audible range.

- They are cryptically colored.

- They are wary.

- They have a relatively sporadic distribution (locally abundant) and may occur in low densities in some areas.

- They frequently occur in specific habitats that are difficult to access and sample.

- Its' activity level is closely correlated with ambient air and water temperatures and weather conditions.

To minimize these challenges, and to maximize survey results, a clear understanding of the natural history of the northern leopard frog is required. Much of the information and suggestions below can be applied to other amphibian species; however, it is recommended that research into the natural history background for other target species be undertaken prior to the commencement of their respective surveys.

\subsection{Physical description}

The northern leopard frog (Rana pipiens) is a member of the Family Ranaidae or 'true frogs'. Typically, frogs of this family are slender, long-legged jumpers with extensive webbing between the toes on their hind feet. In general, Rana frogs (including the leopard frog) have smooth skin and a pair of raised longitudinal ridges of glandular tissue, called dorsolateral ridges, which are located on the back of the frog and on either side of the spine. The background color of the leopard frog ranges from various shades of green to brown or tan; occasionally a rare golden color morph is described in Alberta (Appendix 1, Photo 1 and Photo 2).

Two key diagnostic features distinguish the northern leopard frog from all other frog and toad species in Alberta (Figure 1). They are:

- A pair of continuous white or cream coloured dorsolateral ridges that extend from behind the eyes to the lower back near the groin.

- Numerous irregularly placed round or oval dark spots with light borders on the back, legs and sides. 
Other field marks include:

- Light line on upper jaw.

- Pale white undersides.

- Vocal sacs paired and situated at the sides of the throat over the forelimbs (undetectable when deflated).

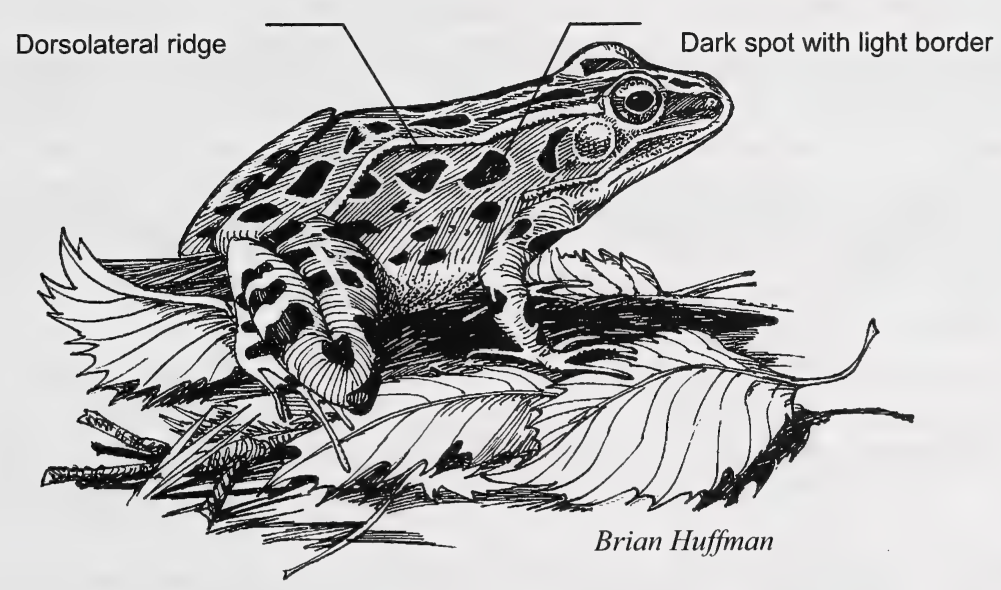

Figure 1. Sketch of a northern leopard frog depicting key diagnostic features.

\subsection{Size and age class differentiation}

The snout to vent length (SVL) is the measured distance between the snout of the frog and the vent of the frog, along its back. The SVL of the leopard frog varies depending on its age and growth rate. Thus, it is largely dependent on acquired nourishment and environmental factors during tadpole development and subsequent time after metamorphosis. As a result, the accurate differentiation of age classes may be limited to adult frogs and recent metamorphs (Table 1). Furthermore, male leopard frogs are innately smaller than female leopard frogs. Therefore, without confirmation of the sex of the observed frog, it may not be possible to reliably distinguish a mature adult male frog from a subadult female frog.

Table 1. Summary of age class and SVL of leopard frogs suggested by a number of authors.

\begin{tabular}{|c|c|l|}
\hline Age class & SVL (range) & Reference(s) \\
\hline adult & 60 to $110 \mathrm{~mm}+$ & $\begin{array}{l}\text { Hine et al. 1981, Conant and Collins 1991, Nace et al. } \\
\text { 1996, Russell and Bauer 2000 }\end{array}$ \\
\hline YOY* & 25 to $45 \mathrm{~mm}$ & $\begin{array}{l}\text { Merrel 1977, Hine et al. 1981, Seburn and Seburn 2000, } \\
\text { Kendell 2001 }\end{array}$ \\
\hline $\begin{array}{c}\text { YOY prior to first } \\
\text { winter }\end{array}$ & $>55$ to $56 \mathrm{~mm}$ & Merrell 1977, Seburn and Seburn 2000 \\
\hline
\end{tabular}

* Young-of-the-year (YOY) frog or metamorph at first emergence. 
To limit discrepancies in the ageing of leopard frogs observed in the field, the following SVL measurements should be followed as a rough guide.

- Frogs $>60 \mathrm{~mm}$ (to $110 \mathrm{~mm}+$ ) can be considered adult frogs.

- Frogs $>45 \mathrm{~mm}$ but $<60 \mathrm{~mm}$ can be considered subadult frogs.

- Frogs $\leq 45 \mathrm{~mm}$ can be considered young-of-the-year (YOY) frogs.

\subsection{Sexual differences}

Male leopard frogs can be distinguished from female leopard frogs by the presence of paired vocal sacs situated at the sides of the throat over the forelimbs. However, these are undetectable when deflated. When not calling male leopard frogs can be sexed by the examination of the thumb (first finger). Male leopard frogs have a swollen inner edge at the base of their thumbs (much enlarged during breeding), while female leopard frogs have thumbs that taper gradually from the palm (Figure 1).
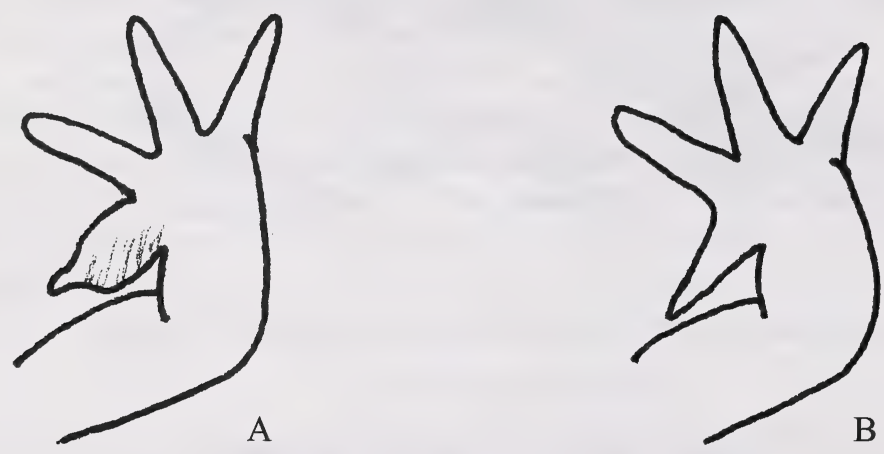

Figure 1. Thumb of male (A) and female leopard frog (B).

\section{$\underline{2.4 \text { Vocalization and spawning }}$}

Both the male and the female leopard frog are capable of emitting sounds, but only the male has a call that is used for breeding purposes. The mating call of the male leopard frog consists of numerous vocalizations, which can be heard simultaneously from a single chorus.

The call is comparable to the sound produced by rubbing a wet finger on a well-inflated balloon, to produce a low snore-like sound. Typically, the call begins with three or more of these snorelike sounds followed by interspersed grunting and chuckling sounds. The duration of the call is variable (one second to several seconds) and may end abruptly. In general, the call starts and ends weakly and because it is rather subdued, it does not carry an appreciable distance and may go unnoticed. The male leopard frog also emits a "release call" that is used during breeding in response to amplexus attempts by other males or as a spacing function between males (Pace 1974). This call can be reproduced in male frogs while held in the hand by touching and gently applying pressure to the back and sides of the frog. Occasionally, female leopard frogs will emit a weak croak when startled or handled. 


\subsection{Phenology}

In Alberta, leopard frogs generally vocalize (call) between late April and early June (BSOD 2001) however more typically they begin to call in April, before the ice has completely melted from many waterbodies. The timing of leopard frog breeding activity (calling events and egg deposition) is strongly dependent on various environmental conditions such as air and water temperature (Brooks 1918, Porter 1972, Hine et al. 1981, Litcht 1991). Latitude, photoperiod and barometric pressure may also influence the initiation and duration of breeding activities. Bovberg (1965) suggests that activity levels may increase with dropping barometric pressure. Also, it is strongly recommended that local ambient temperatures at the time of breeding be considered in conjunction with calendar dates when determining the beginning of the sampling period.

Calling leopard frogs can be heard soon after hibernation when water and air temperatures associated with breeding habitats reach approximately $10{ }^{\circ} \mathrm{C}$ (Wright 1920 , Hine et al. 1981, Kendell 2001). Breeding activity (including calling) can be depressed under cool conditions (below $10^{\circ} \mathrm{C}$ ) resulting in multiple mating periods. It is important to note that breeding may last only a few days or occur intermittently over several weeks, depending on environmental conditions. It is often difficult to accurately identify timelines regarding the initiation of breeding and calling over broad geographical areas. Therefore, a site-specific approach, which takes into account local and current environmental variables, is required.

The deposition of egg masses is usually correlated with calling activity of male leopard frogs. However, male frogs often arrive at breeding sites before female frogs, which may arrive at breeding sites as much as 14 days (usually less) after the males and may take up to seven days to deposit their egg mass (Hine et al. 1981). In Alberta, egg masses have been observed in breeding habitat from late April to early June (BSOD 2001).

\subsection{Identification of egg masses}

Leopard frog eggs are deposited in a mass formation and are distinct from that of toad eggs, which are deposited in strings, and spadefoot eggs, which are deposited in small plum-sized clusters. Typically, anurans will deposit egg masses in close proximity to conspecifics (other amphibian species), which normally occur in habitats that promote egg growth and development.

Each female leopard frog deposits one egg mass, therefore a significant relationship between egg mass counts and number of female frogs can be obtained at the spawning site (Gilbert et al. 1994, Crouch and Paton 2000). The accurate identification of leopard frog egg masses, in areas that overlap with other frog species is possible. In Alberta, the most commonly encountered frog species to co-exist in the same habitat with leopard frogs are the wood frog (Rana sylvatica) and the boreal chorus frog (Pseudacris maculata). Careful examination of the overall size (diameter) and shape of the egg mass in question is required for precise identification (Table 2). 
Table 2. Summary of egg mass size and descriptions of the leopard frog, wood frog and chorus frog as suggested by a number of authors.

\begin{tabular}{|l|c|c|l|}
\hline \multicolumn{1}{|c|}{ Species } & Egg mass diameter & Description & Reference \\
\hline \multirow{2}{*}{ northern leopard frog } & 8 to $13 \mathrm{~cm}$ & grapefruit sized & Corkran and Thoms 1996 \\
\cline { 2 - 4 } & 5 to $15 \mathrm{~cm}$ & irregular globular & Wright 1920 \\
\hline \multirow{2}{*}{ wood frog } & 5 to $7 \mathrm{~cm}$ & plum or orange sized & Corkran and Thoms 1996 \\
\cline { 2 - 4 } & - & globular & Wright 1920 \\
\hline boreal chorus frog & $<2.5 \mathrm{~cm}$ & elongated & Corkran and Thoms 1996 \\
\hline
\end{tabular}

Leopard frog egg masses are usually deposited in shallow water with a depth ranging from 30 to $75 \mathrm{~cm}$ (Eddy 1976, Merrell 1977, Gilbert et al. 1994) and are attached underwater to a stem of emergent or aquatic vegetation, (near the surface of the water). Occasionally, eggs are deposited in water barely deep enough to cover the egg mass. Finally, egg masses are nearly always deposited in areas that are well exposed to sunlight and with high water temperatures relative to the rest of the waterbody.

\subsection{Tadpole identification}

During the early stages of development, it can be difficult to reliably identify a leopard frog tadpole from other species. Physically, leopard frog tadpoles can be distinguished from true toad tadpoles (in Alberta) by the shape and pigmentation of the tail fin shortly after hatch and through metamorphosis. Leopard frog tadpoles have an opaque fin with a tail tip that is pointed whereas toad tadpoles have a clear fin with a rounded tail tip (Figure 2).
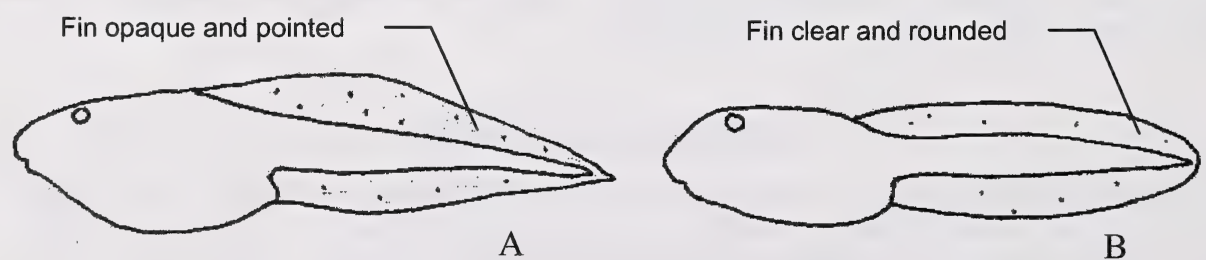

Figure 2. Frog tadpole (A) and toad tadpole (B).

Generally, it is not practical to identify leopard frog tadpoles on the bases of size and color because of the similarity at various stages of development, with other tadpole species. However, leopard frog tadpoles may reliably be identified just prior to metamorphosis when the large size of the tadpole ( $\sim 10 \mathrm{~cm}+$ total length) is unlikely to be confused with other species (pers. obs.). In Alberta, leopard frog tadpoles have been observed in May through the end of August. Typically metamorphosis occurs near the end of July to mid-August and is strongly correlated with water temperature and other factors.

\section{$\underline{2.8 \text { Disease }}$}

One of the most common diseases in frogs is the result of a bacterium known as Aeromonas hydrophila and is commonly referred to as "red-leg". It is nearly always fatal, with spontaneous 
recoveries exceedingly rare. "Red-leg" and other diseases can be triggered at any time in response to stress, injury, malnourishment or environmental conditions such as poor water quality.

A long list of symptoms have been described for this disease, however it is almost impossible to be certain if a given frog has the disease since many of these symptoms overlap with uncomplicated frog behaviour and appearance (Nace et al. 1996). Nevertheless the following, more obvious symptoms are suggested by Nace et al. (1996).

- Slumped posture (palms turned outward).

- Reluctance to move when prodded.

- Tense abdomen.

- Skin haemorrhages (reddish appearance on the underside of the frog's belly and legs).

- Eroded toes and feet with bare bones exposed.

- Damaged skin on the dorsal surfaces (particularly the nose).

\subsection{HABITAT DESCRIPTION}

The northern leopard frog requires three distinct habitat types during it's life cycle:

- A breeding waterbody in the spring for mating, deposition of egg masses, and development of tadpoles (breeding habitat).

- Upland habitat and adjacent habitat near water for foraging during mid-summer (summering habitat).

- A suitable waterbody that does not freeze solid in the winter in which to hibernate (overwintering habitat).

\subsection{Breeding habitat}

Leopard frogs breed in a variety of waterbodies including, marshes, sloughs, dugouts, borrow pits, oxbows, beaver ponds, shallow bays and margins of lakes, quiet backwaters of streams and rivers, slow flowing creeks, roadside ditches and springs (Eddy 1976, Cottonwood Consultants 1986, Wershler 1991, Seburn and Seburn 2000). Ideal breeding habitat possess the following characteristics:

- Some degree of permanence (i.e. unlikely to dry up before tadpoles metamorphose).

- Abundant aquatic and emergent vegetation such as cattails, sedges, rushes, and moisturetolerant grasses that provide cover and a substrate on which to attach egg masses.

- Shallow open water that receives direct sunlight in early morning and afternoon, often on the north side of the pond.

- Standing water that freezes solid during most winters or that may dry up every few years, thereby reducing or preventing the establishment of predatory fish (Merrell and Rodell 1968).

- Non-acidic water with a $\mathrm{pH}$ range between 6.5-8.5 (Nace et al. 1996).

- Shallow water ranging in depth between 10-65 cm (Gilbert et al. 1994). 
- Gradual slopping shoreline to support emergent and adjacent upland vegetation (Wershler 1991).

- Waterbodies with the above characteristics and within $1.6 \mathrm{~km}$ (1 mi) from over-wintering habitat (Wershler 1991).

Upon completion of breeding activities, leopard frogs begin to move into adjacent suitable habitat (summering habitat) or may remain near breeding habitat. Here they find prey and restore fat reserves lost during hibernation, and build up energy reserves for the upcoming winter.

\subsection{Summering habitat}

Adult (post-breeding), subadult (non-breeding) and young-of-the-year leopard frogs (postmetamorphosis) typically spend the summer near water that can be easily reached to escape predators. However, they may also be found a considerable distance (1-2 km) from major waterbodies in areas that have some moisture such as wet meadows, pastures, hay fields, scrub vegetation, sedge meadows, and drainage and irrigation ditches. During summer, frogs tend to select areas with taller vegetation to provide protection from environmental conditions and predators. McAlpine and Dilworth (1989) noted leopard frogs found in vegetation with a mean height of $32.0 \mathrm{~cm}$, and a range of $9-85 \mathrm{~cm}$. Leopard frogs typically avoid heavily wooded areas away from water (Merrell 1977, Hine et al. 1981) and areas with scant cover (i.e. heavily grazed pasture, mowed lawns, recently cut cultivated fields) (Dole 1971, Merrell 1977, Hine et al. 1981). In Alberta, leopard frogs begin to migrate from summering habitat to wintering habitat in September and October (pers. obs.).

\section{$\underline{3.3 \text { Wintering habitat }}$}

The various amphibian species in Alberta have different cold-weather strategies to survive the winter in hibernation. For example, the wood frog and the boreal chorus frog can withstand partial freezing and can survive the winter in microhabitats with minimal cover and protection from the elements. A number of toad species are adapted to burrowing and seek cover in a subterranean retreat shielded from frost.

Leopard frogs typically hibernate in an aquatic environment and require specific water quality parameters. The most basic of these requirements include relatively high dissolved oxygen levels $(7-10 \mathrm{ppm})$, low water temperatures $\left(<4{ }^{\circ} \mathrm{C}\right)$ and a bottom substrate that remains ice-free (Hine et. al. 1981, Cunjak 1985, Nace et. al. 1996). Permanent springs, creeks, rivers, ponds, lakes and other waterbodies that possess these critical parameters may be used for hibernation by leopard frogs. Breeding habitat often occurs along the fringes of deeper waterbodies or in flowing waterbodies, thus allowing leopard frogs to use the same habitats for over-wintering as breeding. If the breeding habitat is unsuitable for over-wintering, the leopard frog must migrate to a more suitable waterbody. These migrations can cover as much as $1.6 \mathrm{~km}(1 \mathrm{mi})$, (Hine et al. 1981, Souder 2000) and occur year after year, as the frogs retrace their route. 


\subsection{METHODS}

\subsection{Pre-field preparation}

- Ensure that the required collection and research permits are obtained or are valid prior to the commencement of any activities requiring permits.

- Specific permits may be required prior to conducting work in National and Provincial Parks, Reserves, Natural Areas or other restricted areas.

- Personnel conducting the surveys must be trained on the selected survey methods and sampling techniques by an experienced individual.

- Personnel must be provided with written survey instructions.

- Personnel conducting the surveys must be evaluated to ensure that they possess sufficient skills to correctly identify amphibians visually and by call. All field personnel should be given written background information on the target species' life history, behaviour and identification. In addition, an audio instructional tape of the various calls of the amphibians of Alberta should be provided. Such a tape can be obtained through the Alberta Amphibian Monitoring Program (http://.gov.ab.ca/env/fw/amphib/index.html).

- Sites to be surveyed should be determined in the office prior to field investigation and specific location coordinates, access routes and directions to the site should be well understood before entering the field.

- It is the responsibility of the survey co-ordinator or individual field personnel to contact all appropriate landholders and authorities prior to the commencement of survey activities.

- Permission must be granted before field personnel access property or land to conduct surveys.

- The appropriate safety equipment (vehicle and personal) must be acquired and check-in plans devise.

- It is strongly recommended that a second individual accompany the person conducting the survey, especially if the survey is conducted at night or in a remote location.

- Assemble all required field equipment needed to complete the survey (see section 7.0).

\section{$\underline{4.2 \text { Recommended survey conditions }}$}

\subsubsection{Time of day}

During breeding, the northern leopard frog is primarily nocturnal. When not breeding the leopard frog may be active any time of day depending on weather and other environmental conditions.

Because leopard frogs are usually nocturnal breeders, call surveys should be conducted only after dark and before $0100 \mathrm{~h}$.

Visual searches for the northern leopard frog may be maximized along open areas of shoreline (near water and cover vegetation) and that are exposed to direct sunlight, particularly in the morning and early afternoon. These areas are frequented by basking frogs and may be especially productive on sunny cool days or during the morning before daytime temperatures increase. Therefore, it is recommended that visual searches be conducted during the morning and early afternoon for basking frogs. 


\subsubsection{Weather}

Surveys should only be conducted under environmental conditions when leopard frogs are most active, resulting in the greatest chance of visual detection. Generally, leopard frogs are most active when air temperatures range between $22-25^{\circ} \mathrm{C}$ and water temperatures range between 18 $24^{\circ} \mathrm{C}$ (Nace et al. 1996). Other ideal weather conditions include calm and sunny periods following rain events or when moisture levels are high such as when vegetation is wet from dew. Environmental and weather conditions that support and depress general activity of leopard frogs are summarized in Table 3.

Table 3. Summary of environmental and weather conditions that affects the activity level of leopard frogs.

\begin{tabular}{|l|l|c|l|}
\hline \multicolumn{2}{|c|}{ Parameter } & Activity & \multicolumn{1}{c|}{ Reference(s) } \\
\hline \multirow{2}{*}{ Water temperature } & $<10^{\circ} \mathrm{C}$ & Low & Brooks 1918, Hine et al. 1981, Litcht 1991 \\
\cline { 2 - 4 } & 18 to $24^{\circ} \mathrm{C}$ & High & Brooks 1918, Nace et al. 1996 \\
\hline \multirow{2}{*}{ Air temperature } & $<10^{\circ} \mathrm{C}$ & Low & Torelle 1903, Porter 1972, Hine et al. 1981 \\
\cline { 2 - 4 } & 22 to $25^{\circ} \mathrm{C}$ & High & Nace et al. 1996 \\
\hline Wind & Calm & High & High winds result in water loss \& desiccation \\
\hline Precipitation & Light/Intermittent & High & $\begin{array}{l}\text { High moisture levels and high relative } \\
\text { humidity favour amphibian activity }\end{array}$ \\
\hline Barometric pressure & Dropping & High & Bovberg 1965 \\
\hline
\end{tabular}

\subsubsection{Time of the year}

In Alberta, August is the preferred month in which to sample for northern leopard frogs because it provides the following benefits:

- Coincides with the metamorphosis of leopard frog tadpoles in most years, thus increasing the probability of encountering frogs because of the greater density of frogs in a localized area.

- The occurrence of YOY frogs could provide important insight into the identification of breeding habitat.

- The occurrence of YOY frogs at a site confirms both breeding activity and breeding success.

- Estimated or relative numbers of YOY frogs observed at a site provides information on the productivity of the breeding habitat and the population.

Note: Late fall surveys are valuable in identifying possible over-wintering habitat.

\subsubsection{Habitat}

To optimize survey results, the habitat searched should correspond with the appropriate time of the year when frogs would be using the habitat.

Considered the following example of a potential leopard frog site to be surveyed, illustrated in Figure 3, where breeding, summering and over-wintering habitats are labelled with a ' $\mathrm{B}$ ', 'S', and ' $\mathrm{O}$ ', respectively. 


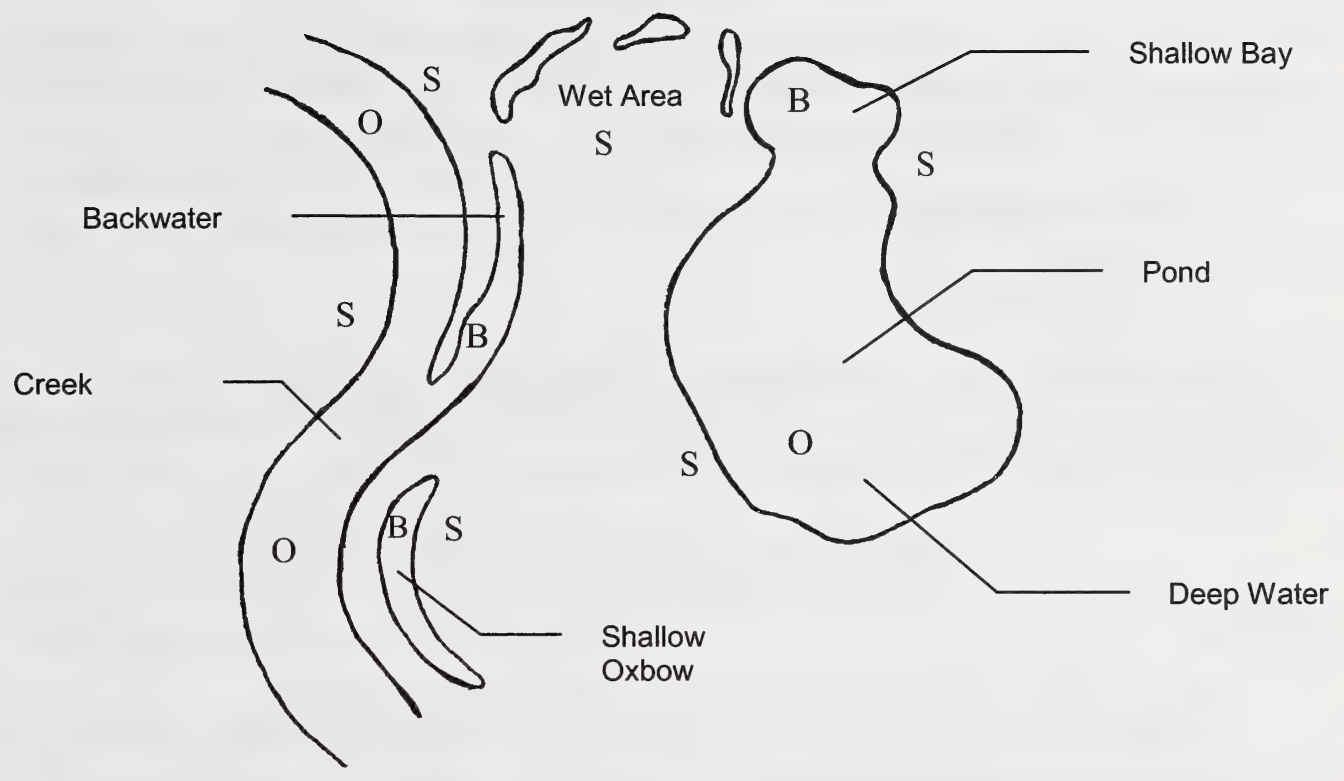

Figure 3. Example of a possible leopard site. Frogs may potentially occur in a number of habitats at the site, depending on the time of the year. $\mathrm{B}=$ breeding habitat, $\mathrm{S}=$ summering habitat, and $\mathrm{O}=$ over-wintering habitat.

Using the example illustrated in Figure 3, a general survey schedule that corresponds to the different habitat types utilized by leopard frogs, can be created (Table 4).

Table 4. Survey schedule based on habitat type and time of the year.

\begin{tabular}{|c|l|l|}
\hline \multicolumn{1}{|c|}{ Habitat Type } & \multicolumn{1}{|c|}{ Dates } & \multicolumn{1}{c|}{ Comments } \\
\hline $\begin{array}{c}\text { Breeding (B) } \\
\text { shallow bay } \\
\text { (pond) } \\
\text { shallow oxbow } \\
\text { backwater of } \\
\text { creek }\end{array}$ & April-May & $\begin{array}{l}\text { Large aggregations of spawning adults, egg masses, } \\
\text { tadpoles and other age classes can be found localized in } \\
\text { specific breeding habitat. }\end{array}$ \\
\cline { 2 - 3 } & June-July & $\begin{array}{l}\text { Typically, frogs will be found in summer habitat at this } \\
\text { time of the year. However, frogs may also occur in or } \\
\text { near breeding habitat with summer habitat attributes. }\end{array}$ \\
\cline { 2 - 3 } & August & $\begin{array}{l}\text { Emergence of a large number of metamorphosed frogs } \\
\text { increases the likely hood of observation, identifies } \\
\text { breeding habitat and confirms successful breeding. }\end{array}$ \\
\hline $\begin{array}{c}\text { Summering (S) } \\
\text { near waterbodies } \\
\text { wet area }\end{array}$ & May-September & $\begin{array}{l}\text { Frogs may be found at low or high densities in summer } \\
\text { habitat depending on the quality and availability of the } \\
\text { habitat. This habitat acts as a transition between } \\
\text { breeding and over-wintering habitats that are disjunct. }\end{array}$ \\
\hline $\begin{array}{c}\text { Over-wintering (O) } \\
\text { creek } \\
\text { deep water (pond) }\end{array}$ & September-October & $\begin{array}{l}\text { Frogs begin to migrate to, and congregate at, over- } \\
\text { wintering sites (i.e. sites with deep water, flow or have } \\
\text { suitable winter water quality). }\end{array}$ \\
\hline
\end{tabular}


The sampling method chosen for the survey will depend on the goal of the study and the question being asked by the investigator. Three sampling methods for the northern leopard frog are described below. They are:

- Timed-constrained visual encounter survey.

- Call survey.

- Egg mass count survey.

The time-constrained visual encounter survey is recommended as the preferred method for sampling leopard frogs. Visual encounter surveys should be conducted in conjunction to, and following the completion of, call surveys and egg mass count surveys.

\subsubsection{Time-constrained visual encounter survey}

GOAL

- Identifying the presence, but not absence, of leopard frogs at a site.

- Investigating currently compiled records held in a database (i.e. BSOD), museum collection or published document.

- Confirmation of anecdotal record(s).

- Field reconnaissance for leopard frogs at suspected sites.

\section{DESIGN}

- Total time spent surveying at the site is recorded (minimum 20 minutes).

- Total area searched at the site is recorded.

- All target species observed at the site are recorded.

- Habitat is systematically walked.

- Surveys are conducted within a narrow period of time (i.e. month or week or day) to minimize differences in habitat use and behaviour of target species resulting from changing environmental conditions.

- If possible, surveys are conducted at the same time of the day for each site.

\section{LIMITATIONS}

- Sites with complex habitat cannot be sampled as efficiently as sites with simple habitat, resulting in a potentially reduced chance of visual encounter.

- Travel, budget and time constraints may result in sites visited at different times of the day or season, and under changing or less than ideal weather conditions, resulting in variable success of visual encounters between sites.

- The number of sites targeted for survey and other logistics such as the number of field personnel available to conduct the survey, timeline to complete the survey and budget (expenses) will determine the amount of time that can realistically be spent at each site.

- Time spent sampling different habitats will require different survey times that reflect the level difficulty and effort needed to sample the site thoroughly. 


\subsubsection{Call survey}

\section{GOAL}

- Identifying the presence, but not absence, of leopard frogs at a site.

- Identifying breeding habitat at a site.

- Identifying breeding activity at a site.

\section{DESIGN}

- Call surveys are conducted at each site from a fixed point located near the most suitable breeding habitat at the site.

- Calling amphibians are recorded using a call index that measures intensity.

- Each call survey will last for 5 minutes.

- Each call survey will begin after sunset (after dark) and end before $0100 \mathrm{~h}$.

- Surveys are conducted within the prescribed breeding period and under the appropriate environmental conditions for the target species.

\section{LIMITATIONS}

- The detection of calling adult frogs at a site provides no information on breeding success.

\subsubsection{Egg mass count survey}

\section{GOAL}

- Identifying the presence, but not absence, of leopard frogs at a site.

- Identifying breeding habitat at a site.

- Identifying breeding activity at a site.

\section{DESIGN}

- Total time spent surveying at the site is recorded.

- Total area searched at the site is recorded.

- Appropriate breeding habitat is systematically walked.

\section{LIMITATIONS}

- Several trips to the same breeding habitat may be required to ensure that all egg masses are inventoried, resulting in the expenditure time and energy in searching the entire waterbody upon each visit.

- Eruptive and potentially intermittent breeding schedule of the leopard frog (based on environmental conditions during the breeding period) may disrupt surveys and result in additional unplanned visits to the site.

- Egg masses may be concealed by vegetation, turbid water or coated with silt, sediment or algae making them difficult to spot.

- Detection of egg masses at a site provides no information on breeding success. 


\subsection{Survey steps}

\subsubsection{Time-constrained visual encounter surveys}

Prior to the commencement of sampling, all pre-field preparations should have been considered and completed.

STEP 1 (selecting the appropriate habitat)

The first step is to identify the most suitable leopard frog habitat to be surveyed at the site. The habitat selected should complement the time of the year (or season) the survey is being conducted and correspond to the use of the habitat by leopard frogs at that time (see section 4.2.4). Ideally, surveys should be conducted in August and in breeding habitat with summer habitat attributes (see section 4.2.3).

Depending on the goal of the survey, it may be necessary to survey less than ideal leopard frog habitat or habitat that is of poor quality. Nevertheless, the steps forthcoming should be followed.

STEP 2 (beginning the visual survey)

The next step is to begin sampling the selected habitat. The start time and end time must be noted, and a minimum of 20 minutes must spent searching at each site. If no leopard frogs are observed after sampling for 60 minutes, the survey should be ended. The amount of time spent at each site will vary depending on the level difficulty in sampling the habitat and the environmental conditions that affect frog activity during the time of survey.

The habitat should be walked at a constant speed that is conducive to observing frogs under the given habitat characteristics at the site. For example, open habitats with sparse and low vegetation can be walked at a greater speed because the observer is less likely to overlook frogs obscured by vegetation. In contrast, a slower walking speed is required if the habitat possess thicker and taller vegetation. In either case, the observer should walk in a systematic fashion to cover all favourable habitats both thoroughly and equally. A good self test, to ensure that the proper speed and diligence is being used while surveying a habitat, is as follows: The individual conducting the survey should be able to spot less obvious animal life underfoot and within peripheral vision. For example, the individual may observe or hear a mouse scurrying through the grass, a young garter snake basking on a rock, other amphibian species and large insects on the ground, vegetation, water or below the surface of the water.

When sampling the habitat, the observer should incorporate the shallow water zone (to rubber boot depth), the waterline and the shore zone (within 3 meters of the waterline) when possible. In this way, other age classes of leopard frogs may be observed, such as egg masses and larvae (depending on the time of year). Both flowing and standing water can be surveyed in this fashion.

Searches in exceptionally thick vegetation that significantly hamper the observers ability to detect frogs (frogs hidden from view or flee without being heard or observed) should be minimized in favour of more open habitat to maximize the chance of observing frogs. 
Most leopard frogs that are encountered during surveys will be flushed from underfoot, or in close proximity $(1-3 \mathrm{~m})$ to the observer, as the habitat is walked. Care and attention is essential to ensure that observed frogs are not double counted. Exact numbers should be recorded whenever possible, however estimated numbers can be recorded when large numbers are observed at one time, such as during mass emergence of young-of-the-year.

Leopard frogs are especially vigilant and wary amphibians. In response to disturbance or a potential predator the leopard frog will typically flee. The long and powerful hind limbs of the leopard frog make it a very efficient jumper and large specimens can cover considerable distances in a single leap (more than 1 meter). Nearby water is the preferred destination of a fleeing leopard frog. Immediately after jumping into the water, the leopard frog will change direction (underwater) and often swim to the bottom to hide in the mud or vegetation. Once in the water, leopard frogs can be exceedingly hard, if not impossible, to spot and capture, especially if sufficient cover is present. Most frogs will be encountered within a short distance (leap or two) from some type of waterbody. If more than one leap is required to reach water or there is no water nearby, the leopard frog will cover ground by leaping in a zigzag pattern. If water cannot be reached, the leopard frog will head for an alternative source of cover, such as thick vegetation. Conversely, a leopard frog may rely on its cryptic coloration in the face of danger, particularly when ambient temperatures are cool. However, eventually some effort to flee usually occurs.

A long handled net or stick can be used to disturb vegetation and flush frogs. This technique also increases the observer's footprint of disturbance, which may flush more frogs. Because leopard frogs are very well camouflaged in most habitats, the greatest chance of observation will occur when a frog moves in response to disturbance. In many cases, the observer will have only a brief moment to observe and identify a frog. If a frog jumps into the water before it can be observed, a characteristic "plopping" sound can often be heard. In such cases, attention can be directed toward the sound, potentially resulting in a frog observation. Alternatively, the area the "plopping" sound was heard can be mentally noted and revisited in a short time, potentially providing a second chance to observe the frog. Occasionally, a frog may need to be captured to confirm identification or for examination. In such cases, the frog should be handled briefly, then released at the location of capture (see Section 5.0).

STEP 4 (complete the data sheet)

Fill out the data sheet as complete as possible (see Appendix 2 and 3).

STEP 5 (handling of the data sheet)

If applicable, completed data sheets should be photocopied and the original(s) sent to the survey coordinator or person managing the data set. Copies of the data sheets should be retained or forwarded to the appropriate Fish and Wildlife Division office, in the region the surveys took place. 


\subsubsection{Call surveys}

Prior to the commencement of sampling, all pre-field preparations should have been considered and completed.

\section{STEP 1 (selecting the appropriate habitat)}

The first step is to select the most suitable breeding habitat at the site to be sampled (see section 3.1). In some cases, an entire pond might exhibit breeding habitat characteristics. In other situations, breeding habitat may occur in shelter bays or along the shore of a larger waterbody with little other available breeding habitat. In the later case, it may be required that the observer pre-visits the site during the day to accurately locate suitable breeding habitat.

\section{STEP 2 (beginning the call survey)}

The commencement of call surveys should correspond with the appropriate weather and environmental conditions at the intended survey site that are supportive of the breeding activity (see section 4.2). Air and water temperatures and wind speed are the most important factors to consider before conducting the call survey. As previously noted, air and water temperatures must be at least $10{ }^{\circ} \mathrm{C}$. Ideally, surveys should be conducted under calm wind conditions (i.e. no wind or gentle breeze). Damp nights or nights with light rain falling are ideal survey conditions. If the survey personnel are not located near the site to be sampled, a local contact person can provide important information on current weather conditions in the intended survey area.

In Alberta, call surveys can begin before the ice has completely melted from many waterbodies and as early as April. But again, only if favourable environmental and weather conditions exist at the breeding site. In most years, it is recommended that survey personnel are available to conduct surveys between early April and late May. If a narrow window of survey opportunity is available to conduct the survey, late April to early May should be selected as the preferred sampling period. Surveys should be aborted if they cannot be conducted under optimal conditions and attempted again later. Survey personnel should be prepared to conduct surveys on any evening that is suitable within the breeding period of the target species. To minimize the chance of missing calling activity, it is important that the surveys commence within a few days of the first suitable survey conditions at the site. Calling activity will begin as soon as the correct environmental and weather conditions occur at the site and may last only for one or two evenings. Thus, if sampling is delayed, the target species could be missed.

Call surveys must be conducted after dark and completed before $0100 \mathrm{~h}$. Upon arrival at the site to be surveyed, the observers should position themself optimally to achieve the best vantage point to detect calling frogs. For example, standing down-wind of the habitat being surveyed may yield a more productive survey, as the wind will carry the sound of the calling frogs to the observer. Before conducting the call survey, the observer must wait until the disturbance created upon their arrival subsides ( 5 minutes) before beginning the survey. Survey personnel should also position themselves as close to breeding habitat as possible without disturbing calling behaviour and activity. Each survey will last for 5 minutes. 
The audio detection of calling frogs is recorded on the data sheet using a call index that categorizes the intensity of calling activity into five call levels:

1. None heard

2. Individual counted or one frog is heard calling at the site.

3. Individuals counted. Two or more calling frogs are detected at the site, but with no overlapping calls. For example, individual males can be counted and their calls do not start at the same time.

4. Several individuals are heard calling at the site simultaneously. Under this code the calls are overlapping but still distinguishable (i.e. individual frogs can be detected in the chorus).

5. Full continuous chorus. Under this code the calls are overlapping and are not distinguishable (i.e. individual frogs can not be detected in the chorus, rather a continuous "blur" of sound is heard).

The following should be considered when estimating the number of calling leopard frogs and their relative positions within the breeding habitat, at the site.

- Male frogs are somewhat territorial and therefore usually do not call from the exact same location.

- Larger or older males may have a deeper or stronger call than smaller or younger males.

- The position of vocalizing frogs, in relation to the water (i.e. if the vocal sacs are above the water or semi-submerged underwater), may effect the tone or sound of the call.

Survey personnel should be cautious of the following situations:

- Conducting call surveys proximal to ambient noise (i.e. busy highway, pump station, etc.) may affect the observers ability to hear calling frogs.

- Exceptionally loud choruses of other frog and toad species can interfere with one's ability to detect calling leopard frogs (this should be noted on the data sheet).

- High winds and heavy or persistent rain may reduce calling activity and interfere with the observer's ability to accurately hear calls.

- Only one observer interprets and records data during the call survey.

STEP 4 (complete the data sheet)

Fill out the data sheet as complete as possible (see Appendix 2 and 3).

STEP 5 (handling of the data sheet)

If applicable, completed data sheets should be photocopied and the original(s) sent to the survey coordinator or person managing the data set. Copies of the data sheets should be retained or forwarded to the appropriate Fish and Wildlife Division office, in the region the surveys took place. 


\subsubsection{Egg mass counts}

Prior to the commencement of sampling, all pre-field preparations should have been considered and completed.

STEP 1 (selecting the appropriate habitat)

The first step is to select the most suitable breeding habitat at the site (see section 3.1) and microhabitat for the deposition of egg masses (see section 2.6). Other conditions that should be considered include conducting the surveys under sunny weather conditions (to improve visibility below the water surface) and under calm wind conditions (minimize rippling effect of the water surface, that may result in reduced visibility and disturbance of sediment that may obscure egg masses).

\section{STEP 2 (searching for egg masses)}

The observer should carefully and systematically walk in breeding habitat to ensure all appropriate habitat is thoroughly searched. Sampling should begin at the water line and continue to at least boot level of water depth and not exceed $65 \mathrm{~cm}$ of water depth. A slow and gentle pace will help to ensure egg masses are not trampled and minimize disturbance to the substrate and water surface that could obstruct the view of egg masses.

When walking through the water, the observer should walk against the direction of the water flow or the wind, if present. In this way, the observer will minimize the effects of the cloud of sediment and debris that may be created by the disturbance of the substrate, thus ensuring good visibility into the water ahead of the observer.

Attention should be focussed on areas with emergent vegetation that may provide a substrate for egg mass attachment. If no emergent vegetation is present and in exceptionally shallow water, egg masses may be deposited directly on the bottom of the pond (attached to aquatic vegetation or debris).

\section{STEP 3 (detecting egg masses)}

Each egg mass is to be counted only once. It may be necessary to flag the location (i.e. securing a flag to the emergent vegetation in which the egg mass is attached to or near) of each egg mass to ensure that they are not double counted. Precise mapping of the site and egg mass locations may be a preferred alternative to flagging egg mass locations. The flag's presence may draw the attention of cattle or other wildlife, resulting possible depredation or trampling of the egg mass.

STEP 4 (complete the data sheet)

Fill out the data sheet as complete as possible (see Appendix 2 and 3).

STEP 5 (handling of the data sheet) 
If applicable, completed data sheets should be photocopied and the original(s) sent to the survey coordinator or person managing the data set. Copies of the data sheets should be retained or forwarded to the appropriate Fish and Wildlife Division office, in the region the surveys took place.

\subsection{AMPHIBIAN HANDLING}

It is recommended that observers/researchers not handle leopard frogs or other amphibians unless absolutely necessary. Occasionally, however, the need to handle an amphibian during sampling may arise. Such examples include the identification of the species or the confirmation of the species sex or age class. Other incidences may include investigating and examining for suspected disease and other possible abnormalities.

Since amphibians have sensitive, porous skin, when handling an amphibian, it is imperative that the hands are free of bug repellent, suntan lotion and other chemicals. Latex gloves can be used when hands cannot be cleaned sufficiently. Even the salt in human perspiration can irritate an amphibian's skin. To reduce the chance of injury by handling the delicate skin of an amphibian, hands should always be moistened prior to touching the animal. Egg masses and tadpoles should always be handled very gently while in water.

\subsection{AMPHIBIAN DISEASE INVESTIGATION}

\subsection{Pre-field preparation}

- The laboratory that will be examining the specimens must be contacted before specimens are collected and sent.

- Laboratory personnel and the Pathologist can provide information on general guidelines for transporting specimens (i.e. packaging and timing) and the most suitable preservation and storage methods for a specimen.

- Refer to the Canadian Cooperative Wildlife Health Centre's (CCWHC) Wildlife Disease Investigation Manual or contact the CCWHC for more information on the collection, handling and transporting of specimens (1-800 567-2033).

\subsection{Specimen preservation methods}

\subsubsection{Cooler}

Live specimens or recently deceased specimens can be kept cool and transported to the laboratory in a cooler without being frozen. Specimens shipped in this manner are of most value for examination and provide the greatest potential for making a diagnosis. 


\subsubsection{Ice}

If a specimen cannot be transported to the laboratory in a reasonable amount of time, it may be necessary to freeze it. Once the specimen is frozen it must not be allowed to thaw before it is examined. If the animal must be killed, it is essential that recognized and approved methods be used in the euthanasia process (i.e. quick and painless).

\subsubsection{Chemical preservatives}

A number of chemical preservatives are available for use of preserving and storing specimens collected in the field. The preferred chemical will depend on the type of examination to be performed. Before a preservative is chosen advice from the laboratory should be obtained. It should also be noted that these chemicals are hazardous substances and should be handled with care and stored and disposed of correctly. Possible preservatives include:

- $10 \%$ Neutral Buffered Formalin.

- $70 \%$ Ethanol.

\subsection{Specimen information}

All specimens should be labelled using waterproof tags with information written on them with either permanent pen or soft lead pencil. A tag should be attached to specimen and duplicate tag should be attached to the container or bag holding the specimen.

Information that is submitted with each specimen must include:

- Full name and complete contact information of the person who collected the specimen(s).

- Age, sex and type of species involved.

- Number of specimens collected.

- How the specimen was found (i.e. alive, dying, dead) and if killed, how it was killed.

- General description of the waterbody or site and specific location (UTM coordinates) of from which the specimens were collected.

- Date of the collection.

- Possible environmental or habitat conditions that may have contributed to the incident (i.e. agriculture runoff, industrial plant nearby, dry weather conditions).

- Your predictions on the situation from what you know about the specimen and its surroundings.

\subsection{Preventing the spread of disease}

Precautions should be followed if a sampling site is suspected to contain diseased animals. To prevent the transfer of infectious agents to other areas, all nets, rubber boots, and other equipment that has come into contact with the diseased animal or contaminated water at the site must be carefully cleaned of mud, vegetation, and other debris. These items must then be disinfected with a $20 \%$ bleach-to-water solution before leaving the site. The disinfectant solution can be applied to equipment using a large spray-bottle (commonly used to mist houseplants) to provide an even and thorough application. 


\subsection{REQUIRED EQUIPMENT}

- Long-handled net for ID confirmation, disturbing vegetation to flush frogs, etc.

- Thermometer for recording water and air temperatures.

- Latex gloves for handling amphibians (optional).

- Spray-bottle for applying disinfectant (bleach/water) to field equipment and gear.

- Proper preservatives for the preservation of collected specimens.

- GPS unit and/or 1:50000 topographical maps.

- Rubber boots and/or hip waders.

- Camera and binoculars.

- Data sheets, plastic clip board (for data sheets) and more than one pencil.

- Various safety equipment - personal and vehicle (i.e. first aid kit, flashlight, maps, compass, etc.).

- Plastic bags for specimen collection.

- Waterproof tags for labelling specimens collected for examination and/or disease testing.

- $100 \mathrm{ml}$ and $200 \mathrm{ml}$ rigid containers (ideally plastic) for specimen collection.

- Plastic ruler for measuring SVL to verify age classes (if needed).

- Cell phone or vehicle phone (if possible).

- Extra batteries for applicable equipment. 


\subsection{LITERATURE CITED}

Biodiversity Species Observation Database (BSOD). 2001. Sustainable Resource Development / Alberta Conservation Association, Edmonton, Alberta.

Bovberg, R. V. 1965. Experimental studies on the dispersal of the frog Rana pipiens. Proceedings in Iowa Academy of Science 72:412-418.

Brooks, E. S. 1918. Reactions of frogs to heat and cold. American Journal of Physiology 46: 493-501.

Conant, R., and J. T. Collins. 1991. A field guide to reptiles and amphibians (eastern and central North America), $3^{\text {rd }}$ edition. Houghton Mifflin Company, Boston, NY. 450 pp.

Corkran, C. C., and C. R. Thoms. 1996. Amphibians of Oregon, Washington and British Columbia. Lone Pine Publishing, Quality Colour Press, Edmonton, AB, Canada. 175 pp.

Cottonwood Consultants. 1986. An overview of reptiles and amphibians in Alberta's grassland and parkland natural regions. Unpublished report funded by World Wildlife Fund Canada (Wild West Program), Toronto, ON. 63pp.

Crouch, W. B., and P. W. C. Paton. 2000. Using egg-mass counts to monitor wood frog populations. Wildlife Society Bulletin 28(4):895-901.

Cunjak, R. A. 1985. Winter habitat of northern leopard frogs (Rana pipiens) in a southern Ontario stream. Canadian Journal of Zoology 64:255-257.

Dole J. W. 1971. Dispersal of recently metamorphosed leopard frogs (Rana pipiens) Schreber, in northern Michigan. Ecology 46:236-255.

Eddy, S. B. 1976. Population ecology of the leopard frog, Rana pipiens pipiens Schreber, at Delta Marsh, Manitoba. Unpublished Thesis, University of Manitoba.

Gilbert, M., R. LeClair, and R. Fortin. 1994. Reproduction of the northern leopard frog (Rana pipiens) in floodplain habitat in the Richelieu River, P. Quebec, Canada. Journal of Herpetology 28:465-470.

Hine, R. L., Les, B. L., and Hellmich, B. F. 1981. Leopard frog populations and mortality in Wisconsin, 1974-76. Technical Bulletin No. 122, Department of Natural Resources, Madison, WI. $39 \mathrm{pp}$.

Heyer, W.R., M. A. Donnelly, R. W. McDiarmid, L. C. Hayek, and M. S. Foster (eds.). 1994. Measuring and monitoring biological diversity: standard methods for amphibians. Smithsonian Institution Press, Washington, D. C. 364 pp. 
Kendell, K. 2001. Northern leopard frog reintroduction: Raven River-year 2 (2000). Alberta Sustainable Resource Development, Fish and Wildlife Service, Alberta Species at Risk Report No. 13, Edmonton, AB. 43 pp.

Litch, L. L. 1991. Habitat selection of Rana pipiens and Rana sylvatica during exposure to warm and cold temperatures. American Midland Naturalist 125:259-268.

Pace, A. E. 1974. Systematci and biological studies of the leopard frogs (Rana pipiens complex) of the United States. Ann Arbor: Miscellaneous publications, Museum of Zoology, University of Michigan, No.148.

Pauley, T. K. and M. Little. 1998. A new technique to monitor larval and juvenile salamanders in stream habitats. Banisteria 12:32-36.

Porter, K. R. 1972. Herpetology. W. B. Saunders Company, Philadelphia, PA. 524 pp.

McAlpine, D. F., and T. G. Dilworth. 1989. Microhabitats and prey size among three species of Rana (Anura: Ranidae) sympatric in eastern Canada. Canadian Journal of Zoology 67: 2244-2252.

McDiarmid, R. W. 1994. Amphibian diversity and natural history: an overview. Pp. 5-15 in W. R. Heyer, M. A. Donnelly, L. C. Hayek, and M. S. Foster (eds.), Measuring and monitoring biological diversity: standard methods for amphibians. Smithsonian Institution Press, Washington, D. C. 364 pp.

Merrell, D. J., and C. F. Rodell. 1968. A comparison of the estimated size and the "effective size" of breeding populations of the leopard frog, Rana pipiens. Evolution 22:274-283.

Merrell, D. J. 1977. Life history of the leopard frog, Rana pipiens, in Minnesota. University of Minnesota Bell Museum of Natural History. Occupational Paper No. 15. 23 pp.

Nace, G. W., D. D. Culley, M. B. Emmons, E. L. Gibbs, V. H. Hutchison, and R. G. Mckinnell. 1996. Amphibians: guidelines for the breeding, care and management of laboratory animals. A report of the Subcommittee on Amphibian Standards, Committee on Standards, Institute of Laboratory Animal Resources and National Research Council National Academy of Sciences, Washington, DC.

Russell, A. P., and A. M. Bauer. 2000. The amphibians and reptiles of Alberta. A field guide and primer of boreal herpetology, second edition. University of Alberta Press, Calgary, AB. 279 pp.

Seburn, C. N. L., and D. C. Seburn. 2000. Status Report: northern leopard frog Rana pipiens (Western population). Committee on the Status of Endangered Wildlife in Canada. $43 \mathrm{pp}$. 
Souder, W. 2000. A plague of frogs: the horrifying true story. Library of Congress Cataloguing-in-Publication Data, New York, NY. 299 pp.

Torelle, E. 1903. The response of the frog to light. American Journal of Physiology, Vol. 4, No. 6, Pp. 466-488.

Vial, J. L., and L. Saylor. 1993. The status of amphibian populations. A compilation and analysis. IUCN/SSC Declining Amphibian Population Task Force, Working Document No. 1 , Corvallis, OR.

Wagner, G. 1997. Status of the Northern Leopard Frog (Rana pipiens) in Alberta. Alberta Environmental Protection, Wildlife Management Division, Wildlife Status Report No. 9, Edmonton, AB. 46 pp.

Wershler, C. 1991. Status of the northern leopard frog in Alberta-1990. Alberta Forestry Lands and Wildlife. Unpublished Report, Edmonton, AB.

Wright, A. H. 1920. Frogs: their natural history and utilization. Bureau of Fisheries, document No. 888. Washington Government Printing Office, Washington, DC. 44 pp.

Zug, G. R. 1993. Herpetology: an introductory biology of amphibians and reptiles. Academic Press, San Diego, CA. 
Appendix 1. Photographs of the northern leopard frog.

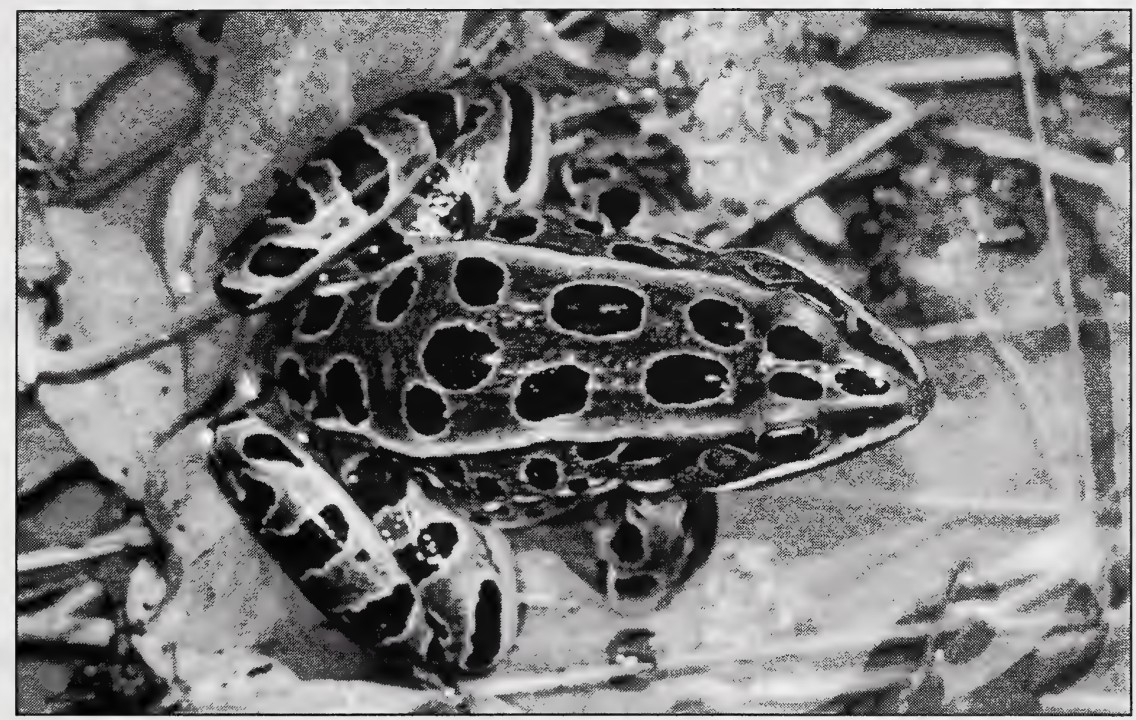

Photo 1. Brown phase of the northern leopard frog. Key diagnostic field marks are clearly shown in the photo, including the lightly colored dorsolateral ridges (on either side of the spine), dark spots with light borders and light line on the upper jaw.

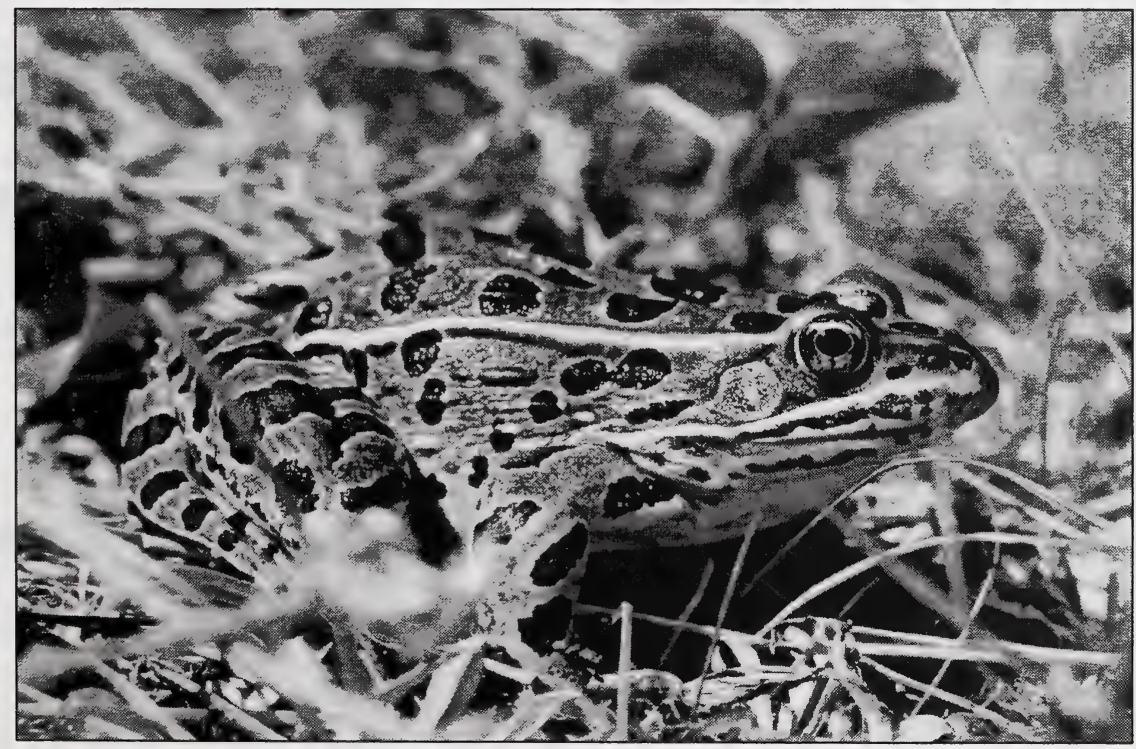

Photo 2. Green phase of the northern leopard frog. 
Appendix 2. Northern leopard frog survey data sheet.

\section{Northern Leopard Frog Survey Data Sheet}

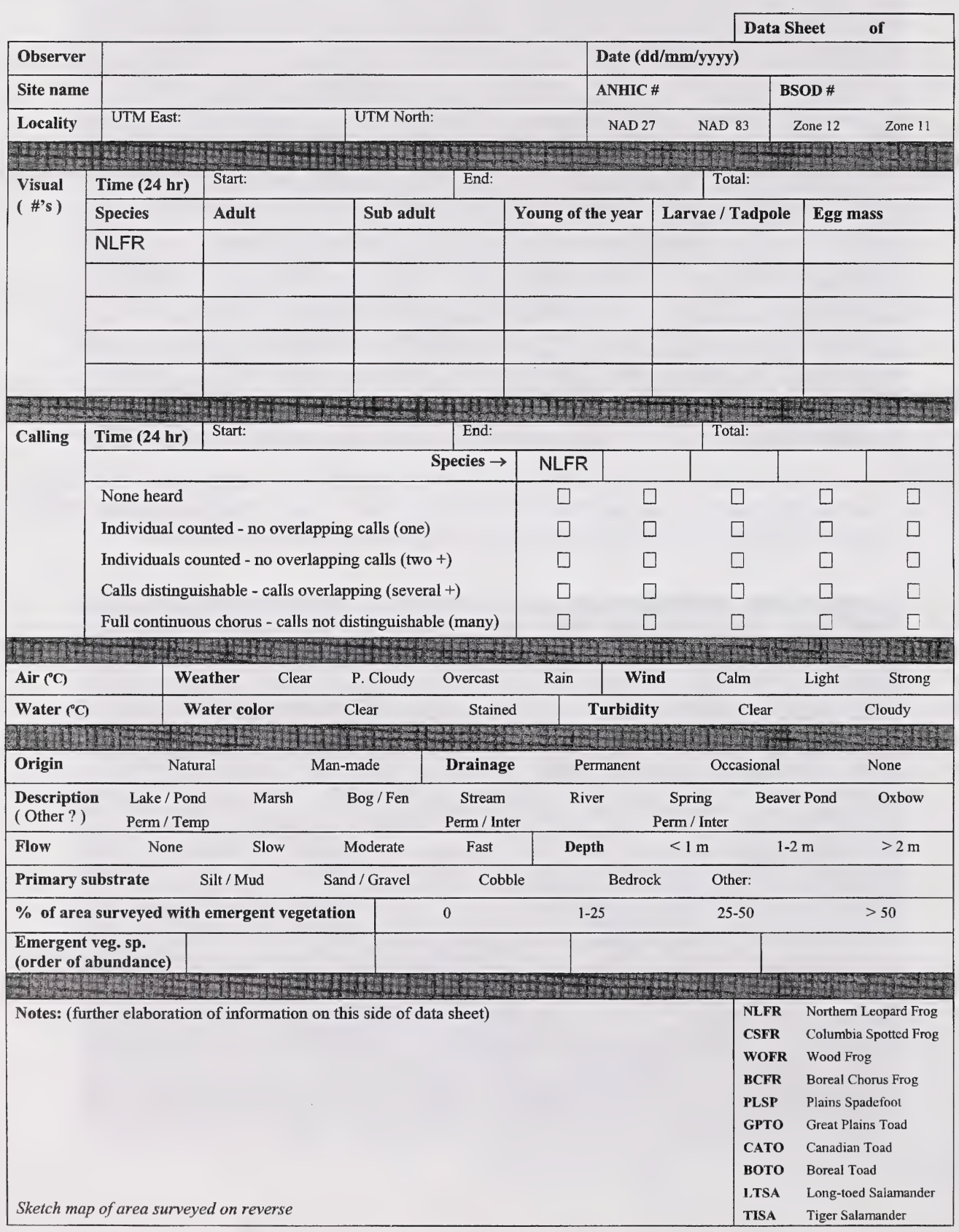




\section{Site Map:}

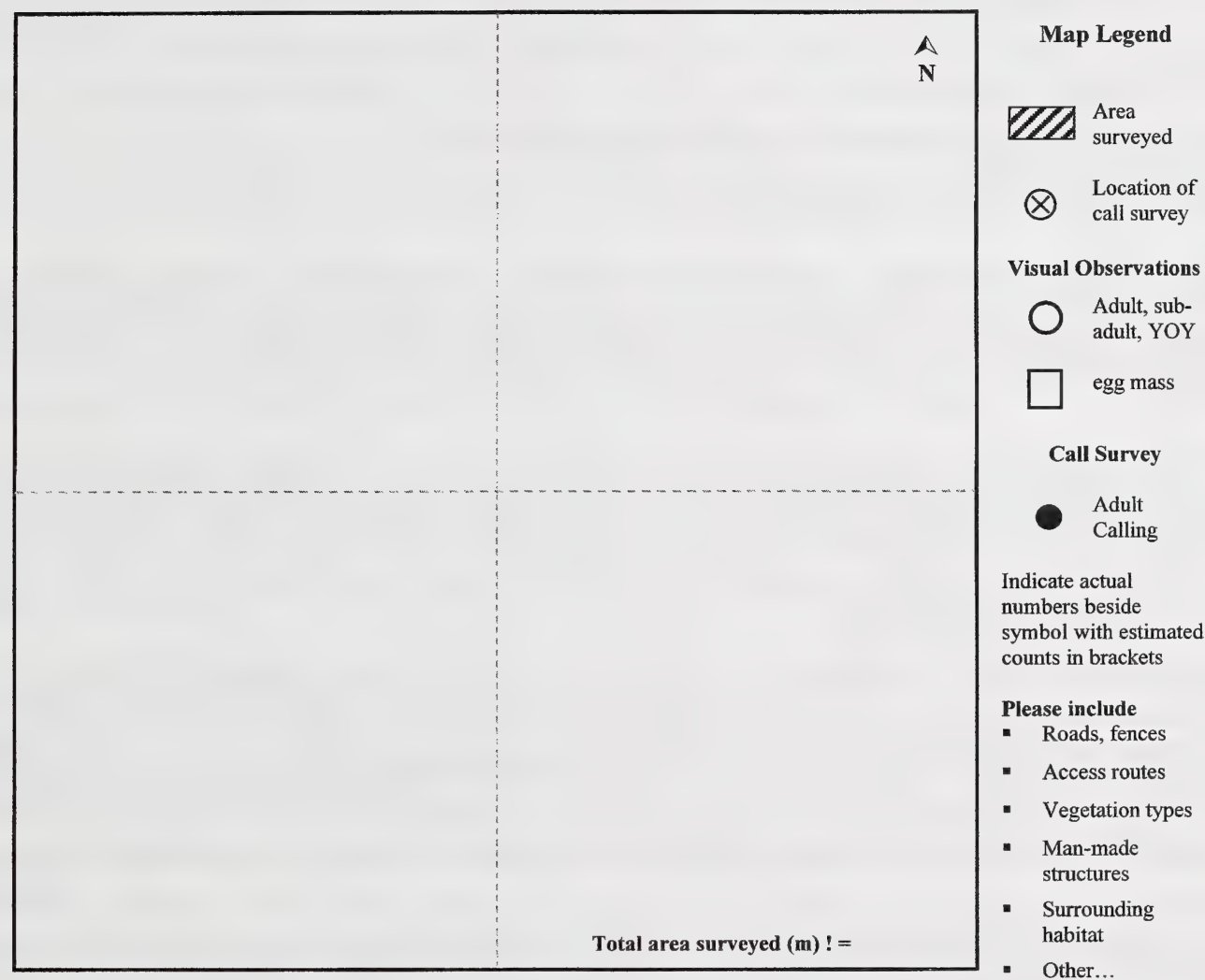

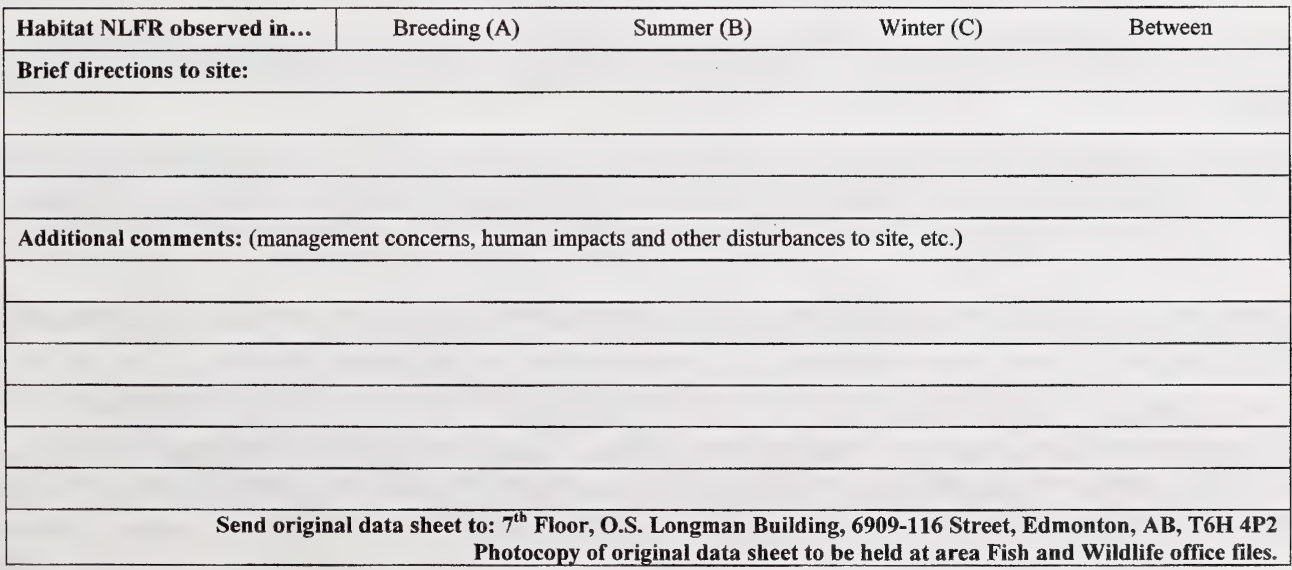




\section{Appendix 3. Interpretation of northern leopard frog survey data sheet.}

Data Sheet_of_: Must be filled out when more than one data sheet is needed at a given survey site. More than one data sheet may be required under the following situations: when a large area is surveyed and the habitat characteristics significantly change and/or when an additional locality coordinate is required; when more than one call survey is conducted at a site or when more space is required to record additional observations or other notes and comments.

Observer: Full name of the individual or individuals conducting the survey.

Date: Recorded numerically - day, month and year.

Site name: The site name should be as specific and brief as possible - one word or short sentence. Permanent landmarks and entities, towns, waterbodies, roadways etc. that are related to the site surveyed are good descriptors that can be incorporated into the site name. The site name will support information supplied with an original BSOD or ANHIC record (if applicable). The site name also helps to ensure the authenticity of the locality coordinates on the data sheet.

Locality: Recorded exclusively in Universal Transverse Mercator (UTM) format (Easting and Northing) to facilitate continuity of data and ease of coordinate conversion, mapping and subsequently data entry into BSOD or other database. Most topographical maps use the 1927 North American Datum (NAD) but are slowly being revised to 1983 NAD, therefore either NAD 27 or 83 can be used, but must be specified. Preference should be given to NAD 83. The UTM grid zone must also be specified as Zone 11 or Zone 12 (in the case of Alberta). A GPS unit or 1:50 000 topographical map will be required.

Visual observations: The start and end time of the survey is recorded along with the total time spent searching (time is recorded in 24-hour format). A total of five different species of amphibians can be recorded on one data sheet. Alberta Environment Taxonomic Codes are to be used in place of the full species name. A list of these codes for amphibians occurring in Alberta is located in the lower right corner of the first side of the data sheet. The age class of each species observed should be specified as adult, subadult, young-of-the-year, larvae/tadpole or egg mass. In the case of larvae/tadpole and egg mass, the prefix UK can be used if species identification is unknown.

Call surveys: The start and end time of the call survey is recorded (total time will be $5 \mathrm{~min}$ ). All time is recorded in 24-hour format. A total of five different species of amphibians can be recorded on one data sheet (see above). For simplicity, the detection of calling amphibians are recorded under five call categories (see data sheet).

Air temperature: Shade temperature (if possible) should be taken at approximately 1 meter above the ground. Temperature is recorded in Degrees Celsius using a standard scientific dry bulb thermometer or other reliable thermometer.

Weather: Recorded as clear, partly cloudy (p. cloudy), overcast or rain directly over head of survey location. The interpretation of weather is subjective and further elaboration on the intensity and degree of participation (rain), for example, may need to be expanded in the notes section of the data sheet.

Wind: Recorded as calm, light or strong and is left to the interpretation of the observer (refer to the Beaufort Scale Appendix 4).

Water temperature: Water temperature may vary greatly throughout a waterbody and is directly affected by a number of variables and the location of the measurement. Thus, it is recommended that water temperatures be recorded a few inches below the surface of the water in an area that may be frequented by amphibians or location of calling activity, egg mass deposition or in the proximity of a general amphibian observation.

Water color: Described as clear or stained. Stained water may result from the presence of natural metallic ions, humus, peat, and decomposition of organic material or by corrosion by-products, such as iron and manganese. Stained water can be described as tea-like in appearance. 


\section{Appendix 3. continued}

Water turbidity: Recorded as clear or cloudy. Turbidity is a water quality term that refers to the cloudy appearance of water, caused by particles or suspended matter. Particles may include debris from plants, animals, clay, silt, and plankton. Turbidity may be caused by soil erosion, algae growth, run off, dredging operations, cattle trampling of the shoreline, etc.

Origin: A waterbody may be natural (river, spring, lake, etc.) or man-made (dugout, dam, lake, drainage ditch, etc.).

Drainage: Refers to the movement of water from the waterbody being surveyed. For example, a permanent stream would have permanent drainage. Many waterbodies exhibit drainage only in the spring or intermittently depending on precipitation and runoff, while others such as some lakes may have no outflow drainage.

Waterbody description: Several common waterbody descriptions are listed on the data sheet (see data sheet). In the case of some waterbody types, it may be necessary to indicate whether or not it is permanent (perm) or temporary (temp) or in the case of streams, rivers and springs whether or not it is permanent or intermittent (inter). Because of a large number of possible waterbody types (for example, dugout, drainage ditch, reservoir, backwater, side channel, etc.), further elaboration in the notes section of the data sheet may be required.

Flow: Recorded as none (lake, pond, etc.) slow, moderate and fast. Choices for this category are limited and subjected to observers personal interpretation of the flow rate, however, it is assumed that participants of the survey will have some experience with the observation of different flow rates of waterbodies and give good judgement.

Depth: Maximum depth of the waterbody being surveyed - may be known or may need to be estimated.

Primary substrate: A number of substrate descriptions are offered on the data sheet. Substrate descriptions observed at the survey site, but not listed on the data sheet should be noted.

$\%$ of area surveyed with emergent vegetation: Percent $(0->50 \%)$ of area surveyed that has emergent vegetation (i.e. cattails, bulrush, sedge, etc.) present.

Emergent vegetation species (order of abundance): List emergent vegetation species in order of abundance, if applicable.

Notes: Use this area to elaborate on required information on the first side of the data sheet. For example, specify drizzle versus rain, dugout as waterbody description, unidentified egg mass observed, lost thermometer, etc.

Site map: Sketch a simple map of the area surveyed that corresponds to the site name and locality. When applicable, suggested legend symbols must be used (see data sheet).

Habitat NLFR observed in...: The observer can choose one of three major habitat types: breeding (A), summer (B) or winter $(\mathrm{C})$. If a specimen is observed in transition between any two of the above choices, the word 'between' must also be circled in conjunction with the two habitats. If the observation occurs in both breeding and overwintering habitat, both summer (B) and winter (C) would be circled.

Brief description to site: This area allows for verbal descriptions on how to access the survey site, which can be used to help survey personnel located the site in future visits. This description should be brief, but precise, and may include highway numbers, landowner names, waterbody names, local names of the site, etc.

Additional comments: Potential or actual threats or management concerns to the site should be identified (for example, cattle impacts, human disturbance, water management practices, upland habitat descriptions, etc.). Anecdotal observations of other species, specimen collected, photograph taken, current landowner, etc. can also be noted. 
Appendix 4. The Beaufort wind scale.

\begin{tabular}{|c|c|c|c|c|}
\hline \multirow[t]{2}{*}{ Code } & \multicolumn{2}{|c|}{ Wind Speed } & \multirow[t]{2}{*}{ Beaufort wind description } & \multirow{2}{*}{$\begin{array}{l}\text { Data sheet wind } \\
\text { descriptions }\end{array}$} \\
\hline & $\mathrm{kph}$ & $\mathrm{mph}$ & & \\
\hline 0 & $0-2$ & $0-1$ & Calm, smoke rises vertically & Calm \\
\hline 1 & $3-5$ & $2-3$ & Light air, smoke drifts & \multirow{3}{*}{ Light } \\
\hline 2 & $6-11$ & $4-7$ & Slight breeze, wind felt on face; leaves rustle & \\
\hline 3 & $12-19$ & $8-12$ & $\begin{array}{l}\text { Gentle breeze, leaves and small twigs in } \\
\text { constant motion }\end{array}$ & \\
\hline 4 & $20-30$ & $13-18$ & $\begin{array}{l}\text { Moderate breeze, small branches sway; dust } \\
\text { and loose paper rise }\end{array}$ & \multirow{3}{*}{ Strong } \\
\hline 5 & $31-39$ & $19-24$ & $\begin{array}{l}\text { Fresh breeze, small trees in leaf sway; thin } \\
\text { branches sway }\end{array}$ & \\
\hline 6 & $40-50$ & $25-31$ & Strong breeze, large branches in motion & \\
\hline
\end{tabular}

Note: shaded portion of table (code 0-3) indicated preferred wind conditions under which to conduct call surveys. 


\section{List of Titles in This Series \\ (as of February 2002)}

No. 1 Alberta species at risk program and projects 2000-2001, by Alberta Sustainable Resource Development, Fish and Wildlife Division. (2001)

No. 2 Survey of the peregrine falcon (Falco peregrinus anatum) in Alberta, by R. Corrigan. (2001)

No. 3 Distribution and relative abundance of the shortjaw cisco (Coregonus zenithicus) in Alberta, by M. Steinhilber and L. Rhude. (2001)

No. 4 Survey of the bats of central and northwestern Alberta, by M.J. Vonhof and D. Hobson. (2001)

No. 52000 survey of the Trumpeter Swan (Cygnus buccinator) in Alberta, by M.L. James and A. James. (2001)

No. 6 2000/2001 Brassy Minnow inventory at Musreau Lake and outlet, by T. Ripley. (2001)

No. 7 Colonial nesting waterbird survey in the Northwest Boreal Region - 2000, by M. Hanneman and M. Heckbert. (2001)

No. 8 Burrowing owl trend block survey and monitoring - Brooks and Hanna areas, by D. Scobie and R. Russell. (2000)

No. 9 Survey of the Lake Sturgeon (Acipenser fulvescens) fishery on the South Saskatchewan River, Alberta (June-September, 2000), by L.A. Winkel. (2000)

No. 10 An evaluation of grizzly bear-human conflict in the Northwest Boreal Region of Alberta (19912000) and potential mitigation, by T. Augustyn. (2001)

No. 11 Harlequin duck monitoring in the Northern East Slopes of Alberta: 1998-2000 preliminary results, by J. Kneteman and A. Hubbs. (2000)

No. 12 Distribution of selected small mammals in Alberta, by L. Engley and M. Norton. (2001)

No. 13 Northern leopard frog reintroduction. Raven River - Year 2 (2000), by K. Kendell. (2001)

No. 14 Cumulative effects of watershed disturbances on fish communities in the Kakwa and Simonette watersheds. The Northern Watershed Project. Study 3 Progress report, by T. Thera and A. Wildeman. (2001)

No. 15 Harlequin duck research in Kananaskis Country in 2000, by C.M. Smith. (2001)

No. 16 Proposed monitoring plan for harlequin ducks in the Bow Region of Alberta, by C.M. Smith. (2001)

No. 17 Distribution and relative abundance of small mammals of the western plains of Alberta as determined from great horned owl pellets, by D. Schowalter. (2001)

No. 18 Western blue flag (Iris missouriensis) in Alberta: a census of naturally occurring populations for 2000, by R. Ernst. (2000)

No. 19 Assessing chick survival of sage grouse in Canada, by C.L. Aldridge. (2000)

No. 20 Harlequin duck surveys of the Oldman River Basin in 2000, by D. Paton. (2000) 
No. 21 Proposed protocols for inventories of rare plants of the Grassland Natural Region, by C. Wallis. (2001)

No. 22 Utilization of airphoto interpretation to locate prairie rattlesnake (Crotalus viridis viridis) hibernacula in the South Saskatchewan River valley, by J. Nicholson and S. Rose. (2001)

No. 23 2000/2001 Progress report on caribou research in west central Alberta, by T. Szkorupa. (2001)

No. 24 Census of swift fox (Vulpes velox) in Canada and Northern Montana: 2000-2001, by A. Moehrenschlager and C. Moehrenschlager. (2001)

No. 25 Population estimate and habitat associations of the long-billed curlew in Alberta, by E.J. Saunders. (2001)

No. 26 Aerial reconnaissance for piping plover habitat in east-central Alberta, May 2001, by D.R.C. Prescott. (2001)

No. 27 The 2001 international piping plover census in Alberta, by D.R.C. Prescott. (2001)

No. 28 Prairie rattlesnake (Crotalus viridis viridis) monitoring in Alberta - preliminary investigations (2000), by S.L. Rose (2001)

No. 29 A survey of short-horned lizard (Phrynosoma hernandesi hernandesi) populations in Alberta, by J. James (2001)

No. 30 Red-sided garter snake (Thamnophis sirtalis parietalis) education and relocation project - final report, by L. Takats (2002)

No. 31 Alberta furbearer harvest data analysis, by K.G. Poole and G. Mowat (2001)

No. 32 Measuring wolverine distribution and abundance in Alberta, by G. Mowat (2001)

No. 33 Woodland caribou (Rangifer tarandus caribou) habitat classification in northeastern Alberta using remote sensing, by G.A. Sanchez-Azofeifa and R. Bechtel (2001)

No. 34 Peregrine falcon surveys and monitoring in the Parkland Region of Alberta, 2001, by R. Corrigan (2002)

No. 35 Protocol for monitoring long-toed salamander (Ambystoma macrodactylum) populations in Alberta, by T. Pretzlaw, M. Huynh, L. Takats and L. Wilkinson (2002)

No. 36 Long-toed salamander (Ambystoma macrodactylum) monitoring study in Alberta: summary report 1998-2001, by M. Huynh, L. Takats and L. Wilkinson (2002)

No. 37 Mountain plover habitat and population surveys in Alberta, 2001, by C. Wershler and C. Wallis (2002)

No. 38 A census and recommendations for management for western blue flag (Iris missouriensis) in Alberta, by R. Ernst (2002)

No. 39 Columbian mountain amphibian surveys, 2001, by D. Paton (2002)

No. 40 Management and recovery strategies for the Lethbridge population of the prairie rattlesnake, by R. Ernst (2002) 
No. 41 Western (Aechmophorus occidentalis) and eared (Podiceps nigricollis) grebes of central Alberta: inventory, survey techniques and management concerns, by S. Hanus, H. Wollis and L. Wilkinson (2002)

No. 42 Northern leopard frog reintroduction - year 3 (2001), by K. Kendell (2002)

No. 43 Survey protocol for the northern leopard frog, by K. Kendell (2002)

No. 44 Alberta inventory for the northern leopard frog (2000-2001), by K. Kendell (2002)

No. 45 Fish species at risk in the Milk and St. Mary drainages, by RL\&L Environmental Services Ltd. (2002) 




National Library of Canada

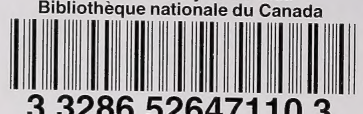

33286526471103 